\title{
CONF-9309528--1
}

\section{The Significance of Chemical Markers in Bioprocessing of Fossil Fuels}

E.T. Premuzic ${ }^{a}$, M.S. Lin ${ }^{a}$, and B. Manowitz

\author{
Department of Applied Science \\ ${ }^{2}$ Biosystems and Process Sciences Division \\ 'Applied Physical Sciences Division \\ Brookhaven National Laboratory \\ Upton, NY 11973
}
Presented at the "Fuel Processing Technology, Fourth International Symposim on Bioprocessing of Fossil Fuels" Proceedings
Alghero, Italy
September 21-23, 1993

Also published in Fuel Process. Technol. 40, 227-239 (1994).

This research was performed under the auspices of the U.S. Department of Energy under Contract No. DE-AC02-76CH00016.

By acceptance of this article, the publisher and/or recipient acknowledges the U.S. Government's right to retain a nonexclusive, royalty-free license in and to any copyright covering this paper. 
The Significance of Chemical Markers in Bioprocessing of Fossil Fuels

\author{
E.T. Premuzica, M.S. Lin', and B. Manowitz
}

aBiosystems and Process Sciences Division, Department of Applied Science, Brookhaven National Laboratory, Upton, New York 11973, U.S.A.

${ }^{b}$ Applied Physical Sciences Division, Department of Applied Science, Brookhaven National Laboratory, Upton, New York 11973, U.S.A.

\begin{abstract}
Biochemical conversion of crude oils is a multi-step process proceeding through a series of biochemical reactions. These reactions can be characterized by a set of chemical markers which are associated with the chemical composition of crude oils. Reactions with heavy crude oils indicate that there is an overall decrease in the concentration and chemical speciation of organic sulfur compounds, and a redistribution of hydrocarbons and organometallic species. The contents of trace metals in the crude oils, such as nickel and vanadium, also decrease. Further, heavy ends of crudes, containing the asphaltenes and the polar nitrogen, sulfur, and oxygen containing fractions, as well as the organometallic compounds and complexes, are biochemically converted to lower molecular weight chemical species. In the studies reported in this paper, microorganisms used to mediate such reactions were thermophilic $\left(>60^{\circ} \mathrm{C}\right.$ ) and pressure tolerant (up to $2500 \mathrm{psi}$ ). These organisms are also capable of biochemical conversion of bituminous and lignite coals in an analogous manner to their action on crude oils and follow similar trends characterized by chemical markers. For example, X-ray Absorption Near-Edge Structural (XANES) analyses of biotreated crude oils and low grade coals show that biochemical reactions lead to decreases in organic sulfides and thiophenes with a concurrent increase in sulfoxide contents. Chemically related constituents present in heavy crude oil fractions and low grade coals are the asphaltenes. Asphaltenes are complex structures containing heteroatoms and metals involved in inter- and intra-molecular bridges and stereochemical configurations. The chemical markers associated with the biochemical conversion of oils and coals indicate multiple biochemical processes involving chemical reactions at sites containing heteroatoms and metals leading to a breakdown of the structure(s) to smaller molecular weight units. Thus, using chemical markers as diagnostic tools, the extent and the efficiency of fossil fuel bioconversion may be predicted and monitored, allowing for better cost-efficient field trials. Recent results in this area will be presented and discussed in this paper.
\end{abstract}

\title{
1. INTRODUCTION
}

Research and development efforts dealing with the biotreatment of crude oils and coals in several laboratories world-wide have led to a number of scientific discoveries and industrial applications. The latter is exemplified by the coal biodepyratization plant in Porto Torres, Sardinia, Italy, and the former by the microbially enhanced oil recovery in the Daqing oil field of China. Concurrently, advantageous properties of microorganisms and 


\section{DISCLAIMER}

This report was prepared as an account of work sponsored by an agency of the United States Government. Neither the United States Government nor any agency thereof, nor any of their employees, makes any warranty, express or implied, or assumes any legal liability or responsibility for the accuracy, completeness, or usefulness of any information, apparatus, product, or process disclosed, or represents that its use would not infringe privately owned rights. Reference herein to any specific commercial product, process, or service by trade name, trademark, manufacturer, or otherwise does not necessarily constitute or imply its endorsement, recommendation, or favoring by the United States Government or any agency thereof. The views and opinions of authors expressed herein do not necessarily state or reflect those of the United States Government or any agency thereof. 


\section{DISCLAIMER}

Portions of this document may be illegible in electronic image products. Images are produced from the best available original document. 
substrates which favor the bioconversion of oils have also been identified, and recently reviewed [1-3]. For example, in the microbial enhanced oil recovery (MEOR), an emerging biotechnology, microbes which can (a) produce metabolites which solubilize oil; (b) produce acids; (c) produce gas; (d) produce emulsifying agents; (e) break down heavy crudes; and (f) live under extreme conditions of temperature, pressure, and salinity--are the microbes of choice. R\&D effort in microbial conversion of fossil fuels has predominantly utilized mesophilic microorganisms, and their effects have been identified [1]. In this laboratory, particular attention has been paid to the effects of organisms active at elevated temperatures and pressures [2]. Thus, current research data indicate that the biotreatment of heavy oils with thermophilic and thermoadapted organisms appears to involve biochemical conversion of asphaltenes via depolymerization at sites containing heteroatoms and metals. Because of the chemical similarity between oil asphaltenes and those of sub-bituminous coals and lignites, similar biochemical conversions of low-grade coals may also be occurring. Preliminary experimental evidence which supports this hypothesis is discussed in this paper.

\section{MATERIALS AND METHODS}

Instrumentation, chemical separation, and methods of analysis have been discussed elsewhere [2-8], and will, therefore, be only discussed briefly in this paper.

(a) Gas Chromatography-Mass Spectrometric (GC-MS) Analysis. A Perkin-Elmer model 8700 gas chromatograph has been interphased with an Ion Trap Detector (ITD), a Flame Ionization Detector (FID), and a Flame Photometric Detector (FPD) for simultaneous mass spectrometric, carbon, and sulfur analysis. This data system encompasses NBS/EPA mass spectral library for identification of unknown samples. In addition to liquid sample analyses, a chemical data system model 190 pyroprobe was used for the pyrolitic solid sample analyses. Each $\mathrm{GC}$ cycle was programmed to start at $50^{\circ} \mathrm{C}$ and the ramp at $8^{\circ} \mathrm{C} / \mathrm{min}$ to $320^{\circ} \mathrm{C}$ and allowed to stay at that temperature for 25 mins. In all cases, a $30 \mathrm{~m}$ capillary column with a $0.25 \mathrm{~mm} / \mathrm{id}$ was used. The column coating was $1 \mu \mathrm{m}, \mathrm{DB}-1$ film and helium was used as the carrier gas at $20 \mathrm{~m} / \mathrm{min}$.

(b) Metal Complexes and Trace Metal Analysis. The samples were digested by nitric vapor ashing method [11]. Solutions of digested samples were analyzed with indium as internal standard. An Inductively-Coupled Plasma Mass Spectrometer (ICP-MS), VG Instruments, was used (Plasma Quad PQ 2+) routinely for the analyses of metals. The instrument is capable of detecting and quantifying up to 70 elements in an analysis with a sensitivity of parts per trillion.

(c) Sulfur Analysis. Total sulfur was determined by combustion to $\mathrm{SO}_{2}$ (Huffman Laboratories, Golden, $\mathrm{CO}$ ). The organic sulfur compounds were monitored by $\mathrm{GC}$ from $40^{\circ} \mathrm{C}-300^{\circ} \mathrm{C}$ equipped with FPD. A J\&W, DB-1 column was used throughout. Overall changes in sulfur speciation were determined by XANES, in the National Synchrotron Light Source (NSLS) facility at Brookhaven National Laboratory (BNL), using the method of Waldo et al. [10]. This analytical method characterizes changes in groups of sulfur compounds present in oil; e.g., sulfides, thiophenes, and sulfoxides. 


\section{CHEMICAL MARKERS: OIL BIOCONVERSION}

Multiple chemical and biochemical processes occurring in a complex medium involve many simultaneous reactions, which in practical terms, cannot be individually isolated and monitored. However, a practical solution to monitor such interactions is to identify signals which characterize an overall sequence of chemical events. These chemical markers are characteristic of a particular set of chemical conversions and transformations peculiar to a complex matrix, which may be organic, inorganic, or a combination of both. Such "chemical markers" are used successfully in oil exploration studies and are known as biomarkers. In fact, they are molecular fossils derived from living organisms and can be found in both oils and source rock bitumines [9]. These compounds can be identified and measured in complex mixtures by a variety of analytical techniques varying from GC-MS analyses to isotope ratios and XANES analyses [10]. The chemical markers are used in the characterization of source rocks, depositional environments, maturity, migration, and the age of source rock. Similarly, within an oil reservoir they can indicate the extent of conversion, for example, due to biodegradation caused by indigenous microorganisms over geological periods of time. R\&D effort at BNL has shown that biotreatment of heavy crudes with thermophilic and thermoadapted microorganisms, involves interactions which fall into identifiable categories and follow recognizable patterns, which are not random and can be monitored by characteristic chemical markers. Several of these will be briefly discussed. In Figure 1, bioconversion of a Boscan crude (a Venezuelan oil) results in conversion of heavier C-30 fractions of crudes to lighter (C-20) hydrocarbons, characterized by a typical GC-MS scan of the mass 57 hydrocarbon chemical marker. Extending this experimental approach to the measurement of the distribution of organo-sulfur compounds by GC, using a sulfur specific detector as shown in Figure 2, indicates that treatment of Cerro Negro, another Venezuelan oil with BNL-4-24, decreases the concentration of organo-sulfur compounds in the oil. Similar studies have been extended to a suite of heavy crude oils [2] all consistently indicating that biochemical conversion of crudes leads to changes in hydrocarbon distribution favoring lighter fractions, a decrease in the concentration of organo-sulfur compounds, and changes in the organometallic composition as shown in Table 1. These studies have shown that the action of a single species of microorganism on a series of different oils, varies. The reverse also holds, namely that the action of different microbial species on the same oil also varies. Some are good metal removers, or good emulsifiers, or good hydrocarbon and sulfur converters, and others are not. For example, the effect of BNL-4-22 and BNL-4-23 on the nickel and vanadium contents of Cerro Negro are shown in Table 1 . Further, deliberately introduced microorganisms seem to act differently from "indigenous ones." Thus, Boscan oil is heavy due to immaturity and Cerro Negro is heavy due to biodegradation by indigenous microorganisms over geological periods of time. The variable effects of introduced organisms on different oils are further exemplified by results shown in Figure 3. In these experiments, two Monterey, California, oils have been used. Monterey A837 is an offshore immature heavy crude, while Monterey A851 is an onshore crude, which is heavy due to biodegradation. Relative to controls, BNL-4-22 and BNL-4-23 efficiently convert heavy hydrocarbons (heavier than C-20) with BNL-NZ-3 being the most efficient bioconverter. In the case of the biodegraded Monterey A851, BNL-4-22 and BNL-4-23 are inefficient and BNL-NZ-3 is highly efficient. Changes in the distribution of organic sulfur compounds are also consistent with previous 
(A)

\section{Before Treatment}

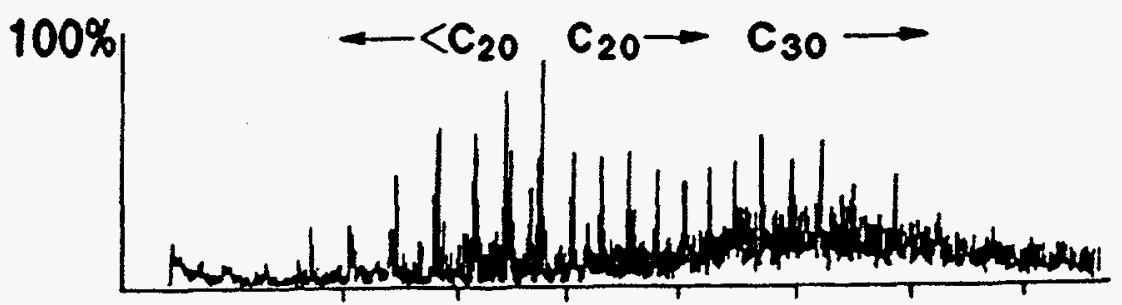

(B)

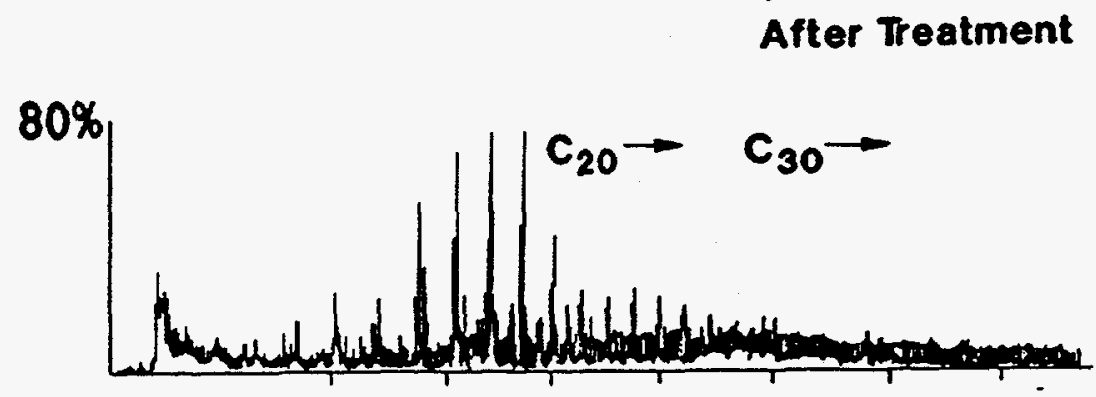

Retention Time

Figure 1. m/e 57 scan of boscan crude: (A) before treatment and (B) after treatment with BNL-4-22.

observations, as shown in Table 2, namely different organisms vary in their effects on the crudes. Further, XANES analysis, a technique which measures the chemical form of sulfur, shows that the types of organic sulfur compounds also change. The formation of sulfoxides and sulfones could be a plausible explanation as the reason for the lowering of the organic sulfur content observed by sulfur specific gas chromatographic analysis. Since sulfoxides and sulfones are soluble in aqueous phase, these forms of sulfur formed by the bioconversion of the initial oil become soluble in the aqueous phase, resulting in the observed overall lowering of the organic sulfur content in the organic (i.e., oil) phase. 


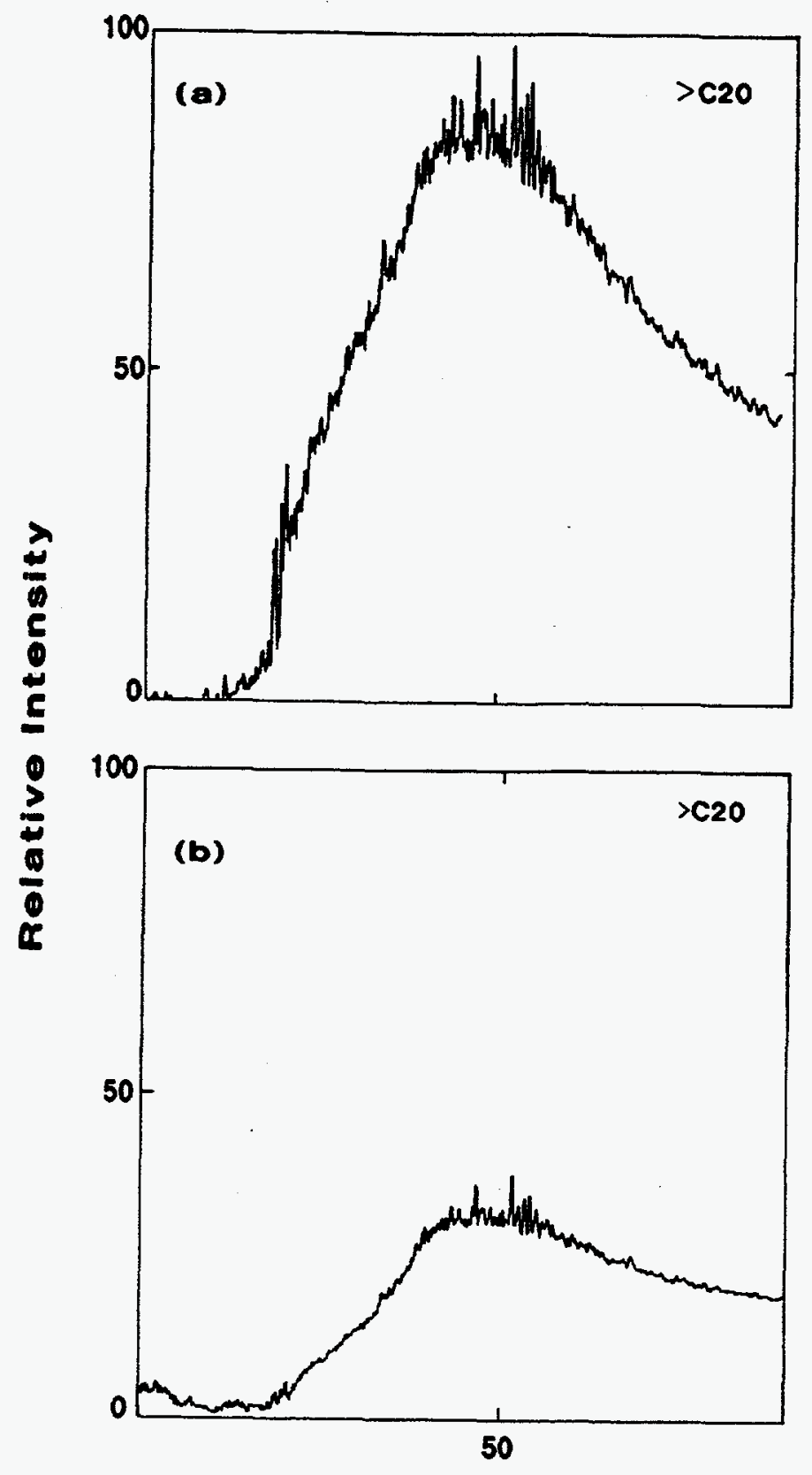

Retention Time

Figure 2. FPD trace of Cerro Negro (a); Cerro Negro treated with BNL-4-24 under identical conditions (b). 
Table 1. Alteration of nickel and vanadium contents in Cerro Negro by different strains of microorganisms.

\begin{tabular}{lcccc}
\hline \multirow{2}{*}{ Microorganisms } & Metal & $\begin{array}{c}\text { Metal Contents of Cerro Negro (ppm) } \\
\text { Treated }\end{array}$ & Untreated & $\begin{array}{c}\text { \% Metal } \\
\text { removed }\end{array}$ \\
\hline \multirow{3}{*}{ BNL-4-22 } & $\mathrm{Ni}$ & 13 & 247 & 95 \\
& $\mathrm{~V}$ & 6 & 494 & 99 \\
\hline \multirow{3}{*}{ BNL-4-23 } & $\mathrm{Ni}$ & 161 & 247 & 35 \\
& $\mathrm{~V}$ & 205 & 494 & 58 \\
\hline
\end{tabular}

Table 2. XANES analyses of Sulfide, Thiophene, Sulfoxide and Sulfone contents of biochemically untreated and treated oils.*

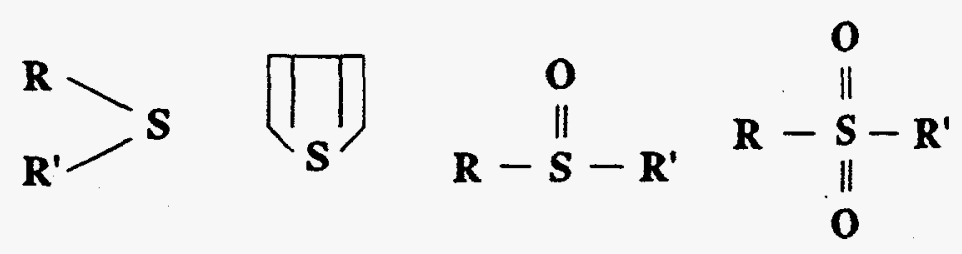

Sulfide Thiophene Sulfoxide Sulfone

Monterey A837

A837 oil, control

A $837+$ BNL-4-22

A $837+$ BNL-4-23

A837+ BNL-NZ-3

0.465

0.480

0.489

0.481
0.440

0.432

0.430

0.413
0.072

0.068

0.064

0.074
0.024

0.022

0.016

0.031

\section{Monterey A851}

A851 oil, control

A851 + BNL-4-22

A851 + BNL-4-23

A851 + BNL-NZ-3

0.457

0.451

0.406

0.481
0.413

0.414

0.418

0.413
0.119

0.122

0.154

0.074
0.011

0.013

0.022

0.031

* Measured in mole fractions. 

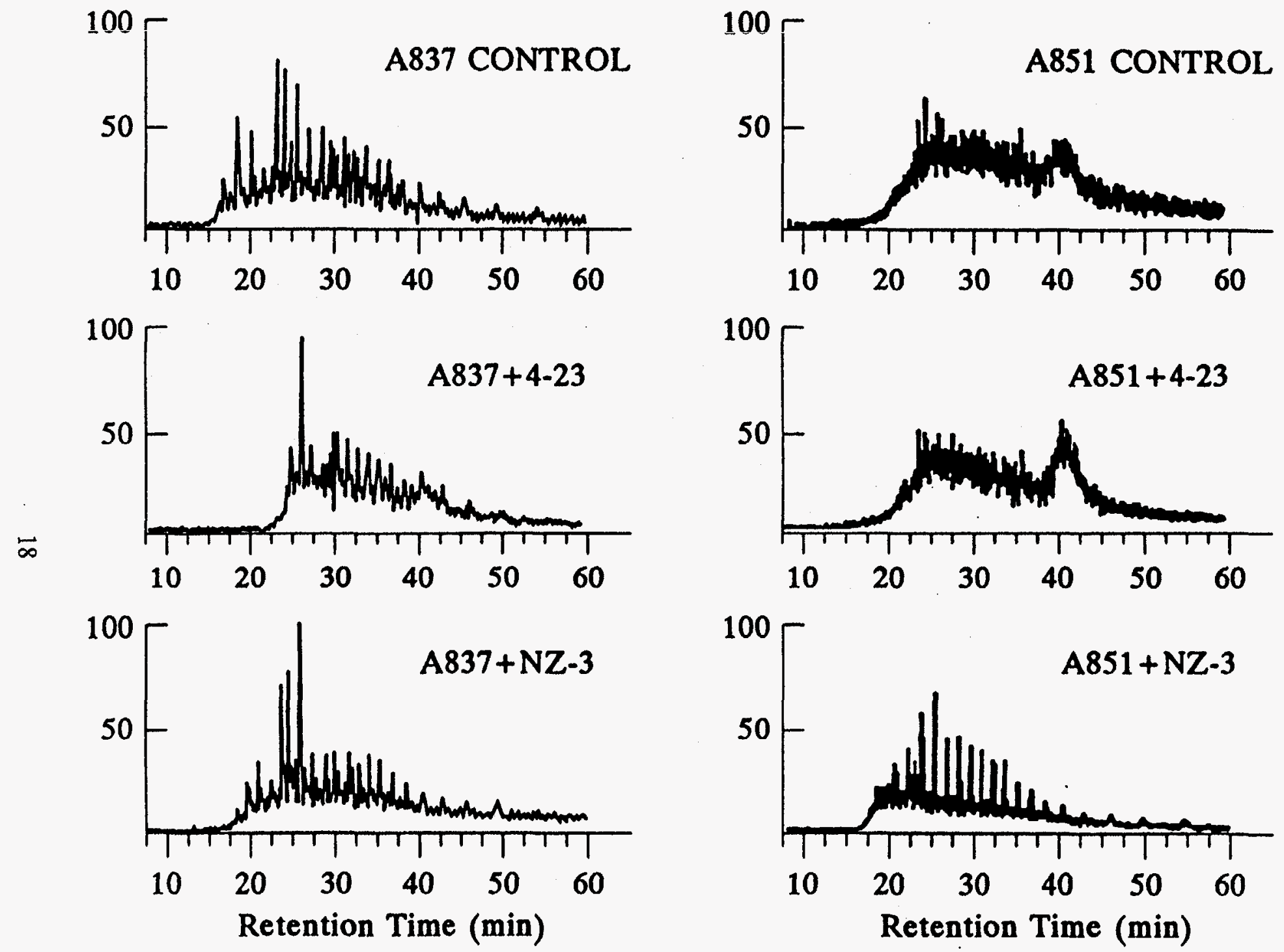

Figure 3. GC-MS fragmentograms, $\mathrm{m} / \mathrm{z}$ 57, Monterey, CA, crude A837 and A851 treated with BNL-4-23 and BNL-NZ-3. 
Table 3. Trace metals contents $(\mu \mathrm{g} / \mathrm{g})$.

\begin{tabular}{lccc}
\hline $\begin{array}{l}\text { Trace } \\
\text { Metals }\end{array}$ & $\begin{array}{l}\text { Untreated } \\
\text { Kentucky No. 8 }\end{array}$ & $\begin{array}{l}\text { Biotreated } \\
\text { Kentucky No. } 8^{*}\end{array}$ & $\begin{array}{l}\text { Percentage } \\
\text { Removal }\end{array}$ \\
\hline $\mathrm{V}$ & 157 & 99 & 47 \\
$\mathrm{Mn}$ & 168 & 41 & 76 \\
$\mathrm{Cu}$ & 143 & 0 & 100 \\
$\mathrm{Sr}$ & 1400 & 1040 & 26 \\
$\mathrm{Y}$ & 80 & 57 & 29 \\
$\mathrm{Zr}$ & 148 & 88 & 40 \\
$\mathrm{La}$ & 83 & 53 & 36 \\
$\mathrm{Ce}$ & 184 & 140 & 23 \\
$\mathrm{~Pb}$ & 76 & 1 & 99 \\
$\mathrm{Th}$ & 34 & 23 & 30 \\
$\mathrm{U}$ & 19 & 0 & 100 \\
\hline
\end{tabular}

Treated with BNL-TH-31.

\section{MECHANISM}

Experimental observations discussed in the previous section suggest that biochemical conversion of crude oils may involve reactions with the heavy ends of crudes and proceed via a depolymerization process, which involves inter- and intra-molecular reactions at active sites containing heteroatoms $(\mathrm{S}, \mathrm{N}, \mathrm{O})$ and metals. The structure of asphaltenes and resins representative of the heavy ends of crude oils are shown in Figure 4a. The association, aggregation, and coalescence of asphaltene and resin units into micelles and multilamelar vesicles [5] through bonding via sulfur, nitrogen, oxygen, and metal bridges, as for example, shown in Figure $4 \mathrm{~b}$, creates a complex, three-dimensional structure. Biochemical reactions at the heteroatoms and bridges would convert such a structure into a less rigid and viscous, lighter hydrocarbon enriched material.

\section{CHEMICAL MARKERS: COAL BIOCONVERSION}

If the mechanistic hypothesis outlined in section 4 is valid, then based on the chemical similarity between asphaltenes and bituminous coals whose typical chemical structure is shown in Figure 5, organisms which act on heavy crude oils should act in a similar manner on low grade coals. Some of the experimental results supporting this hypothesis follow. Thus, changes in the trace metal contents after the biotreatment of Kentucky No. 8 coal are shown in Table 3 and the effects on the sulfur content in Table 4. As the results given in Table 4 imply, particular attention has been given to the differentiation of total, inorganic, and organic sulfur contents. The net result shows an overall lowering in organic sulfur contents. 


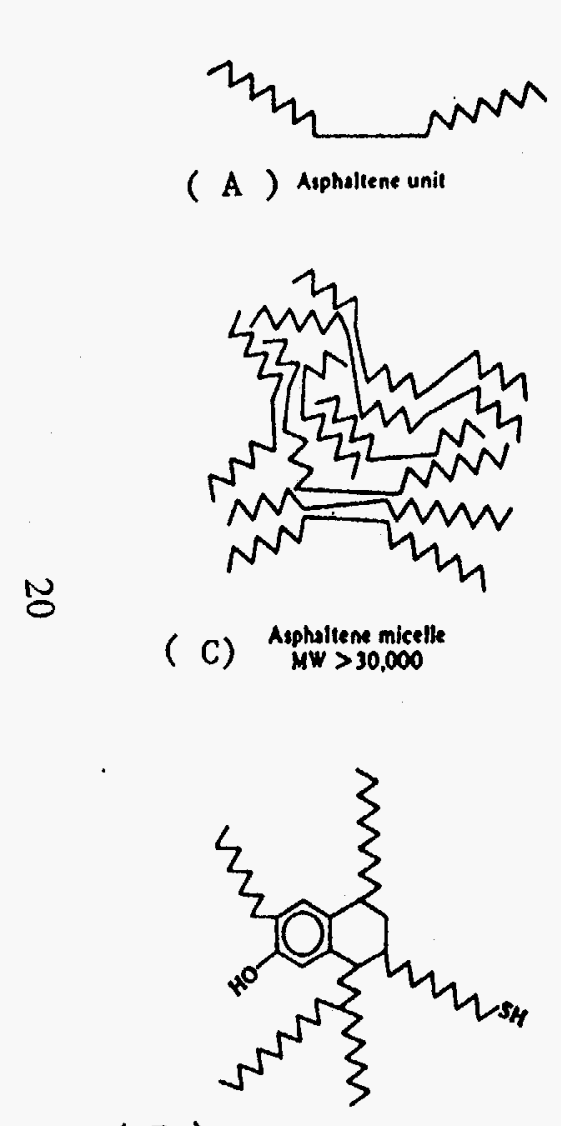

(E) schemalic resin molecule

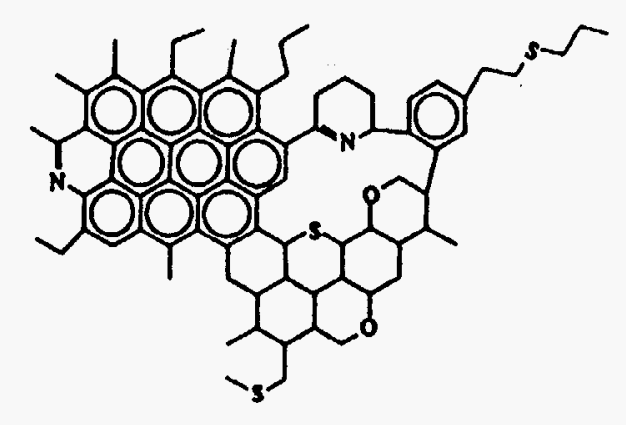

( F ) schematic sighaliene malecule
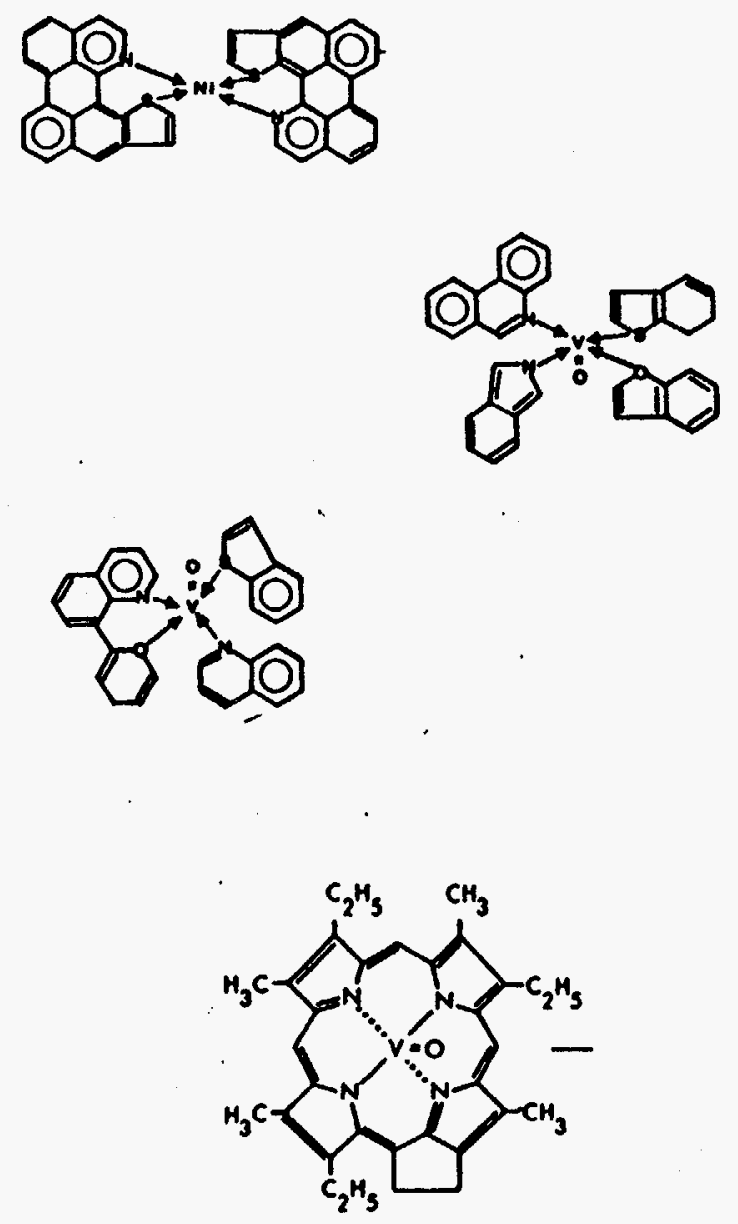

Figure 4(b). Organo-Metallic compounds found in crude oils (after Yen, 1975). 
Table 4(a). Total sulfur removal.

Kentucky No. 8

Bituminous
Panola, MS

Lignite

Biotreatment

-

Control

Mesophilic

BNL-4-23

BNL-4-24

Control

Thermophilic BNL-TH-31

14

24

18

22

28
11

29

21

12

Table 4(b). Inorganic sulfur removal by acid washing $\%$ of total sulfur.

Biotreatment

Kentucky No. 8

Bituminous
Panola, MS

Lignite

Dilute $\mathrm{HNO}_{3}$

Control

Mesophilic

BNL-4-23

Control

BNL-4-24

Thermophilic BNL-TH-31

16

18

42

22

18

47
0

14

26

16

15

Table 4(c). Organic sulfur removal in acid washed coals.

Biotreatment

Kentucky No. 8

Bituminous
Panola, MS

Lignite

Control

Mesophilic

BNL-4-23

BNL-4-24

Control

Thermophilic BNL-TH-31

26

6

2

31

0

12

2

0

9 


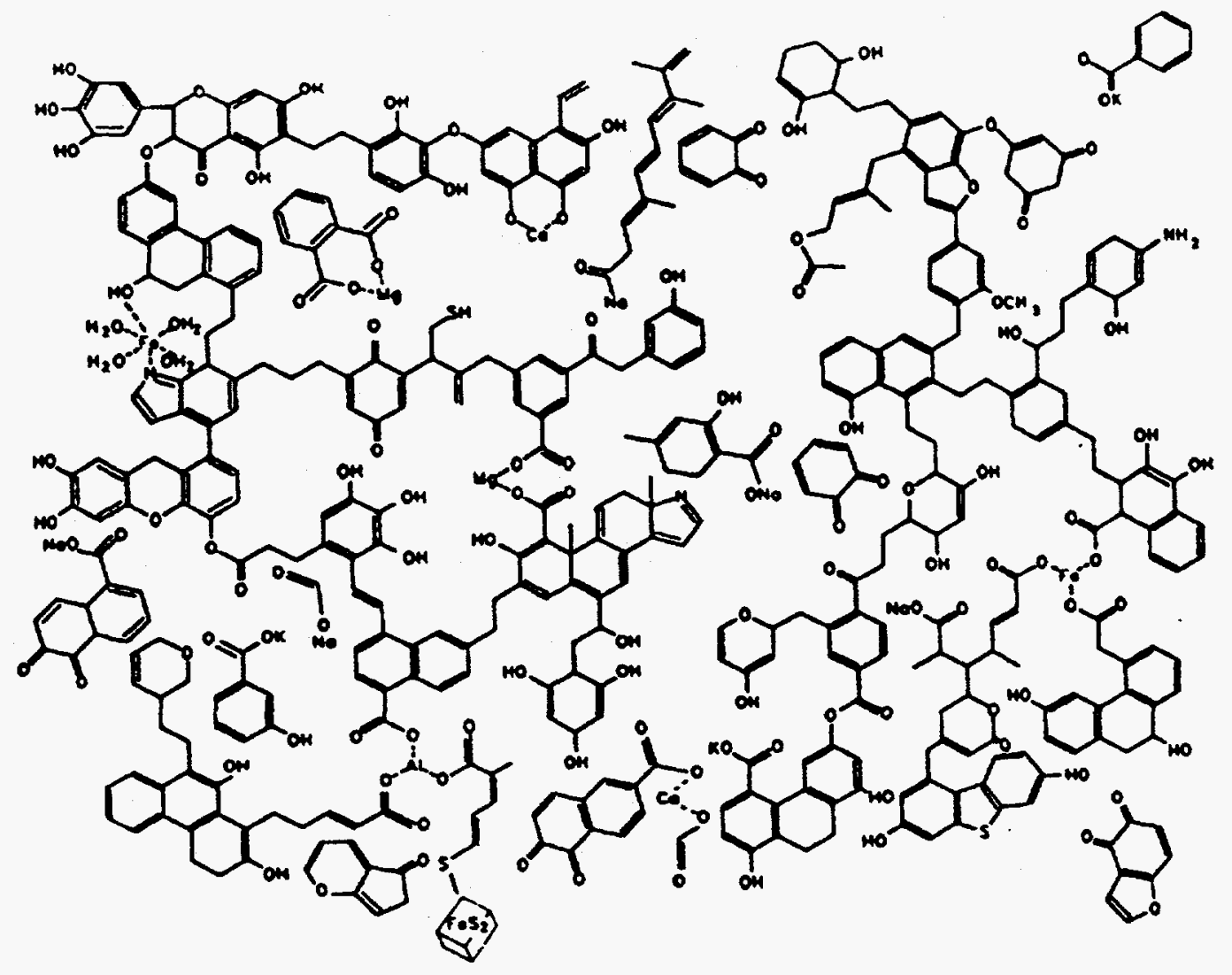

Figure 5. Organic components of low rank coals (after Faison, 1993).
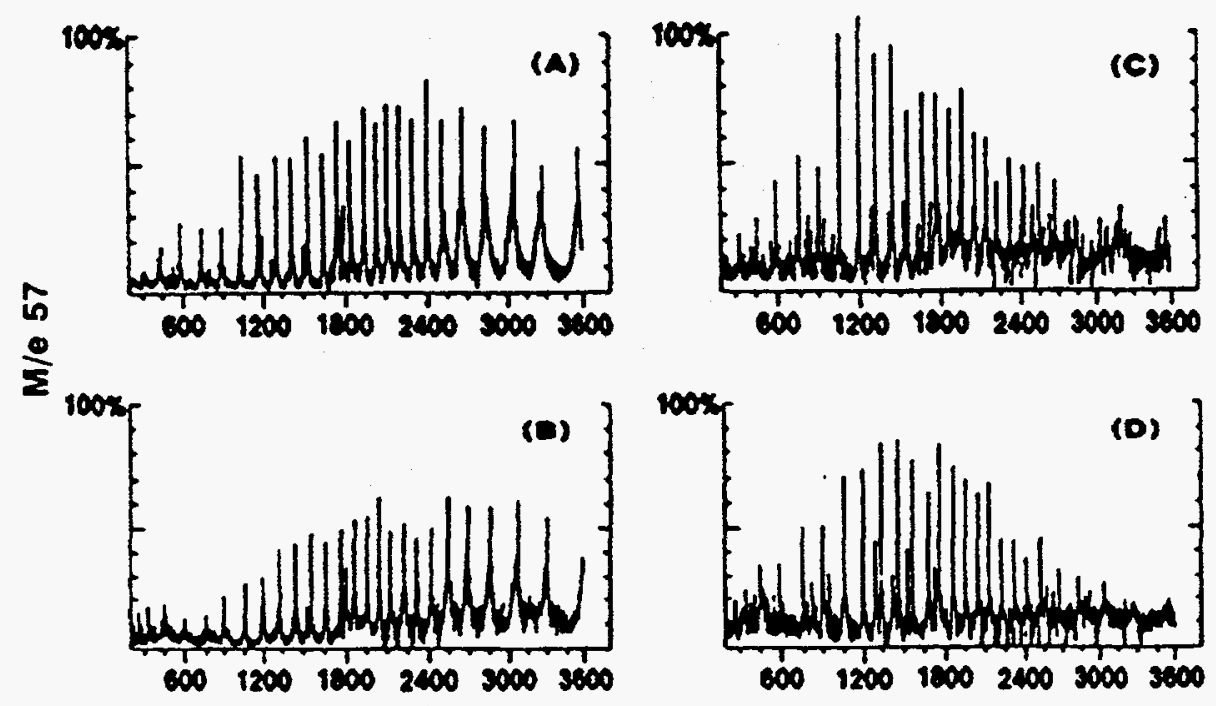

Retention Time, Seconds

Figure 6. Mass 57 hydrocarbon scan of untreated $(A, C)$ and treated $(B, D)$ samples of Kentucky No. 8 and lignite coals. 
Table 5. XANES analysis of biotreated Kentucky No. 8 Bituminous coal.*

\begin{tabular}{lccccc}
\hline & Sulfides & Thiophenes & Sulfoxides & Sulfones & Sulfates \\
\hline $\begin{array}{l}\text { Untreated } \\
\text { BNL-NZ }\end{array}$ & 0.262 & 0.397 & 0.133 & 0.074 & 0.234 \\
$\begin{array}{l}\text { Control } \\
\begin{array}{l}\text { BNL-NZ-3 } \\
\text { Treated }\end{array}\end{array}$ & 0.240 & 0.441 & 0.121 & 0.045 & 0.153 \\
$\begin{array}{l}\text { BNL-NZ-5 } \\
\text { Treated }\end{array}$ & 0.234 & 0.408 & 0.086 & 0.047 & 0.194 \\
$\begin{array}{l}\text { BNL-TH-29 } \\
\text { Control }\end{array}$ & 0.184 & 0.303 & 0.109 & 0.055 & 0.239 \\
\begin{tabular}{l} 
BNL-TH-29 \\
\hline
\end{tabular} & 0.198 & 0.198 & 0.177 & 0.045 & 0.173 \\
\hline
\end{tabular}

${ }^{*}$ Measured in mole fractions.

XANES analyses of biotreated bituminous coal given in Table 5, analogous to that carried out with heavy crudes, are consistent and show variations in the chemical sulfur speciation. Further, hydrocarbon analysis, analogous to those carried out for crude oils, also suggest that biotreatment causes structural conversion and redistribution of hydrocarbons as shown in Figure 6. The GC-MS scan of the mass 57 chemical marker shows qualitative and quantitative changes in the spectra following an enrichment in the lighter, less rigid organic fractions of bituminous coal.

\section{CONCLUSIONS}

Biochemical interactions between microorganisms and heavy crude oils and bituminous coals are:

1. Not random.

2. Follow distinct pathways which can be monitored by chemical markers.

3. The utility and specificity of chemical markers in the studies of oil and coal bioconversion matches that of biomarkers used in oil exploration studies. 
4. Biochemical reactions depend on the chemical nature of the oil and/or coal and the particular microbial species used.

\section{ACKNOWLEDGEMENTS}

This work is supported by the U.S. Department of Energy, Division of Fossil Fuels, under Contract No. AS-219-ECD, and Contract No. DE-AC02-76CH00016 with the U.S. Department of Energy. We wish to thank Mark McCaffrey, Chevron Oil Field Research Company, for the supply of Monterey samples, data, and for valuable comments; and Wai Quing Zhou, BNL/BPSD, for the analysis of XANES data.

\section{REFERENCES}

1. T.R. Jack, "M.O.R.E." to M.E.O.R.: An Overview of Microbially Enchanced Recovery, in "Microbial Enhancement of Oil Recovery--Recent Advances," Proceedings of the 1992 International Conference on Microbial Enhanced Oil Recovery, Eds. E.T. Premuzic and A. Woodhead, Elsevier, Amsterdam, pp. 7-16, 1993.

2. E.T. Premuzic, M.S. Lin, L.K. Racaniello, and B. Manowitz, Chemical Markers of Induced Microbial Transformations in Crude Oils, in "Microbial Enhancement of Oil Recovery--Recent Advances," Proceedings of the 1992 International Conference on Microbial Enhanced Oil Recovery, Eds. E.T. Premuzic and A. Woodhead, Elsevier, Amsterdam, pp. 37-54, 1993.

3. D.L. Crawford, Ed., "Microbial Transformations of Low Rank Coals," CRC Press, Boca Raton, 1993.

4. M.S. Lin, E.T. Premuzic, B. Manowitz, Y. Jeon, and L. Racaniello, Biodegradation of coals, Fuel Journal 72(12), pp. 1667-1672, 1993.

5. J.M. Hunt, "Petroleum Geochemistry and Geology," W.H. Freedman and Co., San Francisco, 1979.

6. T.F. Yen, "The Role of Trace Metals in Petroleum," Ann Arbor Science Publ., 1975.

7. B.D. Faison, The Chemistry of Low Rank Coal and its Relationship to the Biochemical Mechanisms of Coal Biotransformation, in "Microbial Transformations of Low Rank Coals," Ed. D.L. Crawford, CRC Press, Boca Raton, 1993.

8. M.S. Lin, B.J. Sylvester, and E.T. Premuzic, Biochemical Desulfurization and Demineralization of Coals with Mixed Microbial Cultures, in "Proceedings: Second International Symposium on the Biological Processing of Coal," EPRI GS-7482, pp. 7985,1991 .

9. K.E. Peters and J.M. Moldowan, "The Biomarker Guide," Prentice Hall, New Jersey, USA, 1992.

10. G.S. Waldo, R.M.K. Carlson, J.M. Moldowan, K.E. Peters, and J.E. Penner-Hahn, Sulfur Speciation in Heavy Petroleums. Information from X-ray Absorption Near-Edge Structure, Geochimica and Cosmochimica, 55, pp. 801-814, 1991.

11. A.D. Thomas and L.E. Smythe, Rapid Destruction of Plant Material with Concentrated Nitric Acid Vapour (Vapour Phase Oxidation), Talanta 20, pp. 469-475, 1973. 